\title{
Micromorfologia para Caracterização de Processos Deposicionais em Paleocabeceira no Planalto Pinhão/Guarapuava - Paraná
}

\author{
Micromorphology for Characterization of Depositional Processes in a Paleovalley \\ Head in Pinhão Plateau/Guarapuava - Paraná
}

\section{Micromorfología para Caracterización de Procesos Deposicionales en Paleocabecera en la Meseta Pinhão/Guarapuava - Paraná}

\author{
Karina de Cássia Gazola ${ }^{1}$ \\ https://orcid.org/0000-0000-0001-7477-2239 \\ Julio Cesar Paisani ${ }^{2}$ \\ https://orcid.org/0000-0002-8911-6477 \\ Vitor Hugo Rosa Biffi ${ }^{3}$ \\ https://orcid.org/0000-0002-5773-7842
}

\begin{abstract}
RESUMO: Neste trabalho utilizou-se da caracterização micromorfológica para a compreensão dos processos de colmatação de paleocabeceira de drenagem ((paleofundo de vale de zero ordem) na Superfície de Pinhão/Guarapuava. Com base na caracterização macroscópica, foram reconhecidas quatro sequências sedimentares que preenchem a paleocabeceira de drenagem: paleossolo enterrado com topo acumulativo, sequência inferior colúvio-aluvial (co-alúvial), sequência colúvial intermediaria e sequência colúvial superior. Foram coletadas amostras indeformadas para análise micromorfológica, a qual contou com nomenclatura e critérios descritivos de Stoops. Como resultados, verificou-se a distribuição relativa dos constituintes (DRC) do tipo integrada (enáuliporfífica e porfiro-enáulica), sinalizando diferentes fluxos no processo de sedimentação. A DRC enáulica apresenta agregados granulares e, em microagregados, indica escoamento superficial. Já a DRC porfírica exibe microestrutura maciça, sinalizando fluxos densos, possivelmente fluxos de lama. Os materiais que compõem a sequência colúvio-aluvial (co-alúvio), sequência colúvial intermediaria e topo do paleossolo enterrado são provenientes de escoamento superficial. A partir da sequência colúvial superior predominou o processo de fluxos de lama que levou à colmatação da paleocabeceira com a sequência colúvial superior.
\end{abstract}

\footnotetext{
1 Mestrado em Geografia pela Universidade Estadual do Oeste do Paraná. E-mail: karinagazola@gmail.com.

2 Doutorado (2004) em Geografia pela Universidade Federal de Santa Catarina. Professor Associado da Universidade Estadual do Oeste do Paraná. E-mail: juliopaisani@hotmail.com.

${ }^{3}$ Discente no curso de doutorado no Programa de Pós-Graduação em Geografia da Universidade Estadual de Maringá. E-mail: vhugorosabiffi@gmail.com.
} 
PALAVRAS-CHAVE: Colúvio. Co-alúvio. Micromorfologia. Escoamento superficial. Fluxo de lama.

\begin{abstract}
In this study, we made use of micromorphological characterization in order to understand the processes of filling of a paleovalley head (paleo-valley floor of zero order) at the Pinhão Surface / Guarapuava. Based on macroscopic characterization, four sedimentary sequences that fill the paleovalley head were recognized: buried paleosol with cumulative top, lower colluvialalluvial sequence (co-alluvial), intermediate colluvial sequence and superior colluvial sequence. We collected undisturbed samples for the micro-morphological analysis, which counted on nomenclature and descriptive criteria by Stoops. As a result, we identified the constituents related distribution (CRD) of the integrated type (enauli-porphoric and porphyrous-enaulic), points to different streams in the sedimentation process. Enaulic CRD presents granular aggregates and, in micro-aggregates, it indicates sheet wash. Phorphoric CRD, in its turn, exhibits a massive microstructure, pointing to dense stream, possibly mud streams. The materials that compose the colluvial-alluvial sequence (coalluvial), intermediate colluvial sequence and the upper buried paleosol come from the process of sheet wash. From the superior colluvial sequence, the process of mud stream was predominant, and it led to the filling of the paleovalley head with the superior colluvial sequence.
\end{abstract}

KEYWORDS: Colluvium. Co-alluvium. Micromorphology. Sheet wash. Mud stream.

RESUMEN: Este trabajo se utilizó de la caracterización micromorfológica para la comprensión de los procesos de colmatación de paleocabecera de drenaje (paleofondo de valle de cero orden) en la Superficie de Pinhão/Guarapuava. Con base en la caracterización macroscópica, se reconocieron cuatro secuencias sedimentarias que rellenan la paleocabecera de drenaje: paleosuelo enterrado con cima acumulativa, secuencia inferior coluviones-aluviones (co-aluvional), secuencia coluvional intermediaria y secuencia coluvional superior. Muestras indeformadas fueron recogidas para análisis micromorfológico, el cual contó con nomenclatura y criterios descriptivos de Stoops. Como resultados, se averiguó la distribución relativa de los constituyentes (DRC) del tipo integrada (enáuliporfírica y porfiro-enáulica), señalizando diferentes flujos en el proceso de sedimentación. La $D R C$ enáulica presenta agregados granulares y en microagregados, indica escorrentía superficial. Ya la DRC porfírica, exhibe microestructura maciza, señalizando flujos densos, posiblemente flujos de barro. Los materiales que componen la secuencia coluviones-aluviones (co-aluvional), secuencia coluvional intermediaria y cima del paleosuelo enterrado, son provenientes de escorrentía superficial. A partir de la secuencia coluvional superior prevaleció el proceso de flujos de barro que llevó a colmatación da paleocabecera con la secuencia coluvional superior.

PALABRAS-CLAVE: Coluviones. Co-aluviona. Micromorfología. Escorrentía superficial. Flujo de barro.

\title{
INTRODUÇÃO
}

As descrições sistemáticas das formações superficiais em diferentes unidades de relevos revelou-se como um importante instrumento para compreensão da origem e evolução das paisagens planálticas da região sul do Brasil. Os materiais encontrados são tanto de origem alóctone, descritos genericamente como depósitos de colúvio, alúvio e colúvio-aluvio (co-alúvio), quanto de origem autóctone, constituídas por solos e perfis de intemperismo (PAISANI et al., 2019a).

$\mathrm{Na}$ literatura o termo colúvio é utilizado para designar materiais gerados e depositados nos sopés encostas, vinculados a processos tanto de movimento de massa, quanto 
escoamento superficial (THOMAS, 1994). Os colúvios são de suma importância para estudos que abordam a dinâmica e evolução das encostas em contexto geomorfológico que adotam o método processo-reposta, pois indicam fenômenos morfogenéticos, sobretudo quando relacionados às mudanças paleoambientais (LIMA et al., 2017; THOMAS, 1994).

$\mathrm{Na}$ literatura inúmeras pesquisas utilizam-se das propriedades micromorfológicas a fim de caracterizar os aspectos estratigráficos e descrever o comportamento do ambiente às situações alternadas de instabilidades e estabilidades morfo-pedogenética da paisagem (PAISANI; PONTELLI, 2012; PAISANI et al. 2013, 2014, 2016; 2019a). A análise micromorfológica foi aplicada com a finalidade de entender a organização microscópica dos solos, e com ela também se faz possível a caracterização dos materiais alóctones, uma vez que permite reconhecer feições ligadas a processos deposicionais (CASTRO, 2008; CHURCHMAN, 2013; STOOPS, 2003; STOOPS; MARCELINO; MEES, 2010).

Nesse sentido, o objetivo desse trabalho foi identificar as propriedades micromorfológicas dos depósitos sedimentares que colmataram paleocabeceira de drenagem na superfície de Cimeira Pinhão/Guarapuava, inserida no Planalto Vulcânico da Bacia do Paraná, unidade geomórfica dos Planaltos Subtropicais com Araucárias, a fim de compreender os processos genéticos envolvidos no estabelecimento desses tipos de depósitos, bem como reconhecer características dos materiais da área fonte, processos deposicionais e transformações pós-deposicionais.

\section{MATERIAIS E MÉTODOS}

\section{Área de Estudo}

A superfície de Pinhão/Guarapuava localiza-se na borda leste do Planalto das Araucárias (Figura 1), e apresenta dois compartimentos com aspectos aplainados, com vales pouco dissecado pelo sistema hidrográfico do rio Jordão. O primeiro compartimento, a sul do rio Jordão, tem relevo plano a suavemente ondulado, mantido primordialmente por rochas ácidas da Formação Covó. O segundo compartimento, a norte do rio Jordão, exibe relevo suavemente ondulado, mantidos por rochas básicas da Formação Foz do Areia. A leste, a superfície apresenta um terceiro compartimento, com alta dissecação, com relevos acidentados, encostas e vales íngremes (BIFFI, 2019; GAZOLA, 2020).

A paleocabeceira de drenagem está inserida a leste da superfície de Pinhão/Guarapuava, no Terceiro Planalto Paranaense, região Centro-Sul do estado do Paraná e a leste na Bacia Sedimentar do Paraná (GAZOLA, 2020). O substrato geológico da região é constituído de rochas do Grupo Serra Geral - Membro Foz de Areia, e sobre o encontro de zona de falha preenchida por dique de diabásio. O Membro Foz do Areia é 
composto por derrames tabulares espessos de basalto fanerítico cinza, sem evidências de hidrotermalismo, com zona vesícular de topo delgada e descontínua, preenchimentos de quartzo, calcita e zeólita (MINEROPAR, 2013). A cobertura pedológica da região em que se encontra a paleocabeceira foi classificada como Cambissolos que se desenvolveram nas regiões dissecadas da superfície, assim como os Neossolos (EMBRAPA, 1999). O clima da área de estudo corresponde ao tipo $\mathrm{Cfb}$, subtropical mesotérmico úmido, sem estação seca, com verões frescos e inverno moderado (THOMAZ; VESTENA, 2003). Já a paisagem florística da paleocabeceira é denominada como Floresta Ombrófila Mista Altomontana (GAZOLA, 2020); essa vegetação pode ser encontrada em locais com altitudes acima de 1.000 metros e suporta período frio (temperatura média mensal menor ou igual a $15^{\circ} \mathrm{C}$ ) anual mais pronunciado (IBGE, 2012).

Figura 1 - Área de localização da paleocabeceira, inserida na bacia hidrográfica do rio Bananas, região de Guarapuava-PR

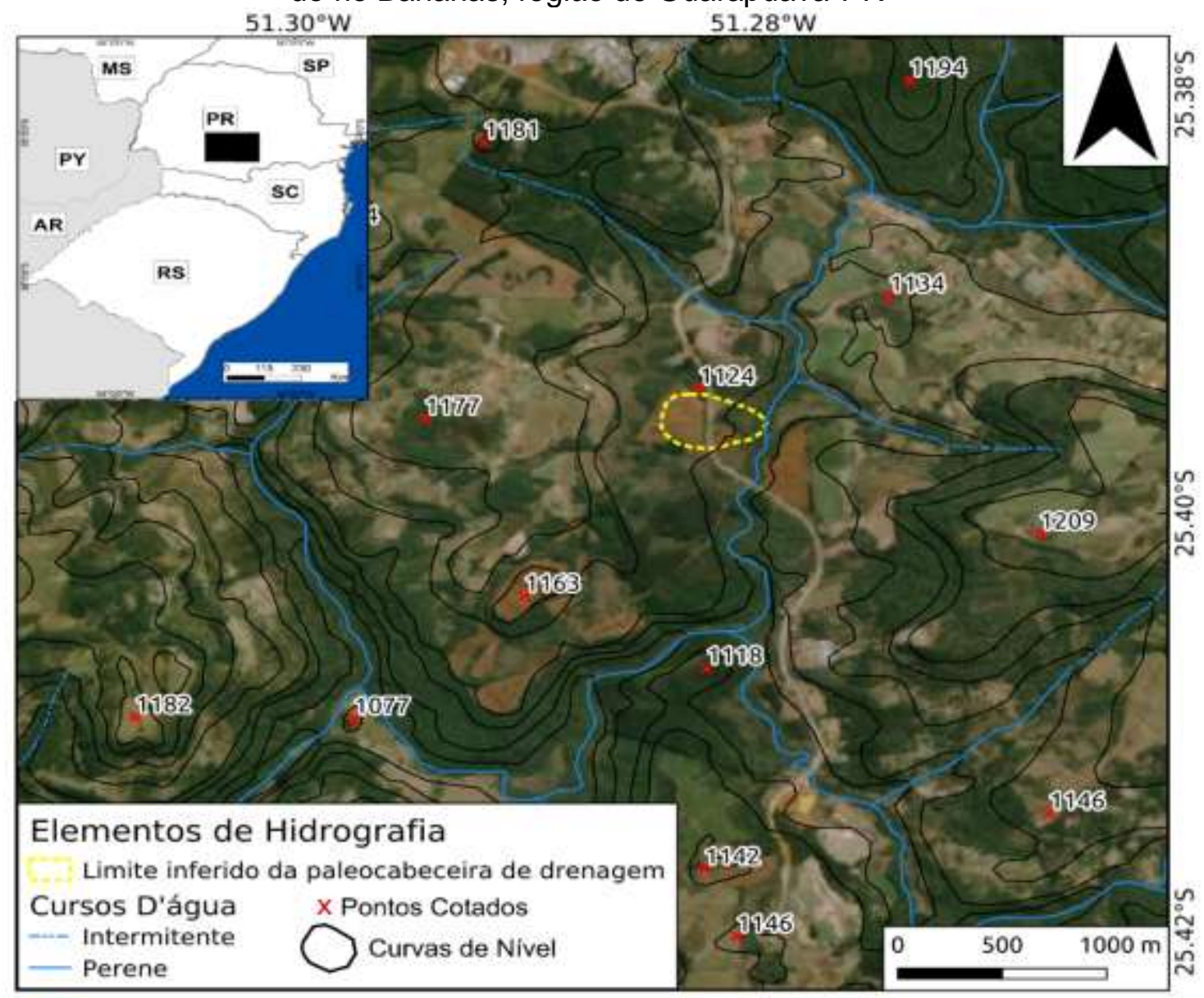

Fonte: Gazola, 2020. 


\section{Procedimentos Operacionais}

Os materiais de colmatação da paleocabeceira afloram em seção estratigráfica exposta em corte de estrada. A seção foi descrita previamente por Gazola (2020) utilizando os métodos lito-, pedo- e aloestratigráficos conjugados (CATT, 1990; HUGHES, 2010). Foram reconhecidos previamente quatro níveis aloestratigráficos, sendo da base para 0 topo, a alterita, caracterizada por apresentar blocos de rocha com alteração esferoidal, preservando parcialmente a estrutura do basalto, e horizonte de cor preto que, em conjunto com a alterita, corresponde ao nível de paleossolo enterrado.

O paleossolo encontra-se truncado lateralmente por feição erosiva linear (paleovoçoroca colmatada). Na base da paleovoçoroca foram reconhecidos sedimentos que constituem a sequência inferior co-alúvial com estratificação tendendo a plano-paralela e presença de pedorrelíquias de epipedon e endopedon. Esse tipo de registro é uma mistura de material de área de encosta (colúvio), e material retrabalhado pela ação da água (alúvio) dentro da voçoroca (PAISANI et al., 2019b). Os registros sedimentares sobrejacentes apresentam estrutura maçica, mas podem ser divididos em duas sequências, uma intermediária e outra superior; sendo esta última a fase final de colmatação generalizada da paleocabeceira de drenagem.

Para a descrição e análise micromorfológica, foram coletadas quatro amostras indeformadas, correspondente ao topo do paleossolo, sequência inferior co-alúvial, colúvial intermediaria e sequência colúvial superior. As amostras foram encaminhadas para o laboratório de Laminação do Instituto de Geociências da USP, onde foram secas em estufa e impregnadas com resina poliéster em temperatura ambiente. Após impregnação foram confeccionadas seções delgadas de até $30 \mu \mathrm{m}$. As descrições e interpretações micromorfológicas foram realizadas no Laboratório de Microscopia Óptica do Núcleo de Estudos Paleoambientais-NEPA/UNIOESTE em microscópio trinocular Leica DM 2500 P, câmera Leica EC3 e o software Leica Application Suíte LAS EZ versão 1.4, e nomenclatura de Stoops (2003) e Stoops, Marcelino e Mees (2010). As análises foram realizadas visando identificar as características e propriedades dos elementos micromorfológicos de cada material e os processos deposicionais e transformações pós-deposicionais (BERTRAN; TEXIER, 1999; MÜCHER; MOROZOVA, 1983; PAISANI; PONTELLI, 2012).

\section{RESULTADOS E DISCUSSÃO}

$\mathrm{Na}$ seção estratigráfica descrita na paleocabeceira de drenagem foram analisadas seções delgadas dos materiais do paleossolo e das sequências inferior (co-aluvial), 
intermediária (coluvial) e superior (coluvial), cujas características e propriedades micromorfológicas seguem no Quadro 1.

Quadro 1 - Propriedades micromorfológicas de sedimentos co-aluviais e colúviais de colmatação de paleocabeceira de drenagem

\begin{tabular}{|c|c|c|c|c|c|c|c|c|}
\hline Amostra & DRC & \multicolumn{2}{|c|}{ Porosidade e microestrutura } & \multicolumn{2}{|c|}{ Fração Grossa } & \multicolumn{2}{|c|}{ Micromassa } & \multirow[t]{2}{*}{ Pedofeicōes } \\
\hline & & Tipos & Micro & Comp & Esfe Arre & Cor & Bircef & \\
\hline $\begin{array}{l}\text { paleosscla } \\
\text { enterrado } \\
\text { (topo) }\end{array}$ & $\begin{array}{l}\text { enauli- } \\
\text { porficica }\end{array}$ & $\begin{array}{c}\text { Canais, } \\
\text { cavitárigs, } \\
\text { vesicularese } \\
\text { planar }\end{array}$ & \begin{tabular}{|c|} 
blocos \\
subangulares
\end{tabular} & $\begin{array}{l}\text { quartzo e nódulo } \\
\text { ittomórico }\end{array}$ & $\begin{array}{c}\text { esférica angular } \\
\text { arredondada e esférica } \\
\text { arredondada alisada }\end{array}$ & 10YR211 & $\begin{array}{l}\text { manchada a } \\
\text { pontilhada }\end{array}$ & pedorreliquia \\
\hline $\begin{array}{l}\text { sequência } \\
\text { inferior co- } \\
\text { aluvial }\end{array}$ & $\begin{array}{l}\text { porfico- } \\
\text { enáulica }\end{array}$ & $\begin{array}{l}\text { empilhamento } \\
\text { complexo, } \\
\text { cavitáco. } \\
\text { e canais }\end{array}$ & granular & $\begin{array}{l}\text { nódulo, quartzo, } \\
\text { imeita, magnefta e } \\
\text { pedorreliquias } \\
\text { (agregados } \\
\text { granulares) }\end{array}$ & $\begin{array}{l}\text { esférica subangular } \\
\text { arredondada e esférica } \\
\text { angular arredondada }\end{array}$ & $2.5 Y R 518$ & $\begin{array}{l}\text { manchas } \\
\text { individuais } \\
\text { pontilhadas }\end{array}$ & $\begin{array}{l}\text { hiporrevestimento de } \\
\text { impregnaçäo, } \\
\text { hiporrevestimento de depleção } \\
\text { e alescomorto }\end{array}$ \\
\hline $\begin{array}{l}\text { sequência } \\
\text { colúvial } \\
\text { intermediaria }\end{array}$ & $\begin{array}{l}\text { porfico- } \\
\text { enáulica }\end{array}$ & $\begin{array}{c}\text { empilhamento } \\
\text { complexo, cavitá } \\
\text { jo e canass }\end{array}$ & $\begin{array}{c}\text { granular e } \\
\text { cavitário }\end{array}$ & $\begin{array}{l}\text { Pedocreliouia, } \\
\text { quartzoilmetita, } \\
\text { magnetita }\end{array}$ & $\begin{array}{l}\text { esférica arredondada } \\
\text { alisada, esférica } \\
\text { suhancular } \\
\text { arredondada, esférica } \\
\text { angular arredondada }\end{array}$ & $2.5 Y R 518$ & $\begin{array}{l}\text { manchada a } \\
\text { pontilhada }\end{array}$ & $\begin{array}{l}\text { Dedorrelíqua Iforcalíqua, } \\
\text { hiporrevestimento de } \\
\text { depleção e quasirtrevestimento } \\
\text { de depleção }\end{array}$ \\
\hline $\begin{array}{l}\text { sequência } \\
\text { colivial } \\
\text { superior }\end{array}$ & $\begin{array}{l}\text { enauli:- } \\
\text { porficitica }\end{array}$ & $\begin{array}{l}\text { cavitánio, planar, } \\
\text { canais e cămara }\end{array}$ & \begin{tabular}{|c|} 
blocos \\
subangulares
\end{tabular} & $\begin{array}{l}\text { nóculo, quartzo, } \\
\text { ilmejita, magnetita, } \\
\text { alterorreliquiag }\end{array}$ & $\begin{array}{l}\text { esférica subangular } \\
\text { arredondada e esférica } \\
\text { angular arredondada }\end{array}$ & $2.5 Y R 518$ & $\begin{array}{l}\text { manchas } \\
\text { agrupadas }\end{array}$ & 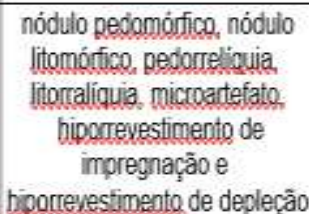 \\
\hline
\end{tabular}

Fonte: modificado de Gazola, 2020.

Os materiais que constituem o paleossolo enterrado apresentam Distribuição Relativa dos Constituintes (DRC) do tipo enauli-porfírica (Quadro 1), implicando que predomina porfírica e localmente é encontrada enáulica. Quando a DRC é porfírica a microestrutura se apresenta em blocos subangulares, enquanto localmente se mostra enáullica em microagregados (Figura 2A-I), composta por aproximadamente $70 \%$ de micromassa, $20 \%$ de poros e $10 \%$ da fração grossa (Figura $2 \mathrm{~A}$ ). Os poros são dos tipos canais, cavitários, vesiculares e planares (Figura 2B, D). A micromassa é caracterizada por apresentar fábrica birrefringente manchada a pontilhada, com cor 10YR2/1 (preta) e 10R5/8 (vermelha). A fração grossa é formada por quartzo e nódulos litomórficos (Figura 2D) de forte a fraca impregnação. Tal fração é mal selecionada com distribuição que ocorre de forma aleatória no fundo matricial. Localmente foram identificados agregados granulares intrusivos (pedorrelíquias), que ocasionalmente se encontram fragmentados por poros canais (Figura 2C, D).

A DRC integrada expressa diferentes categorias de fluxos no processo sedimentar (ARAUJO et al., 2017; BERTRAN; TEXIER, 1999), mas pode decorrer do desenvolvimento de pedalidade por processos biológicos e pedogenéticos (KOOISTRA; PULLEMAN, 2010; MARCELINO; STOOPS; SCHAEFER, 2010). No caso estudado, a ocorrência de agregados granulares esféricos, como pedofeições intrusivas (pedorrelíquias) no fundo matricial é um 
importante indicativo de material de origem alóctone transportado em ambiente de encosta sob escoamento superficial (SELBY, 1985), que promove abrasão dos agregados tornandoos esféricos, conforme constatado em estudo experimental de Wang et al. (2013). Os agregados intrusivos em microestrutura maciça sugerem que o material passou por sucessivos processos de retrabalhamento ao longo da encosta, sendo o processo deposicional final vinculado a discretos movimentos de massa, possivelmente fluxo de lama (BERTRAN; TEXIER, 1999).

Figura 2 - Imagens micrográficas do paleossolo
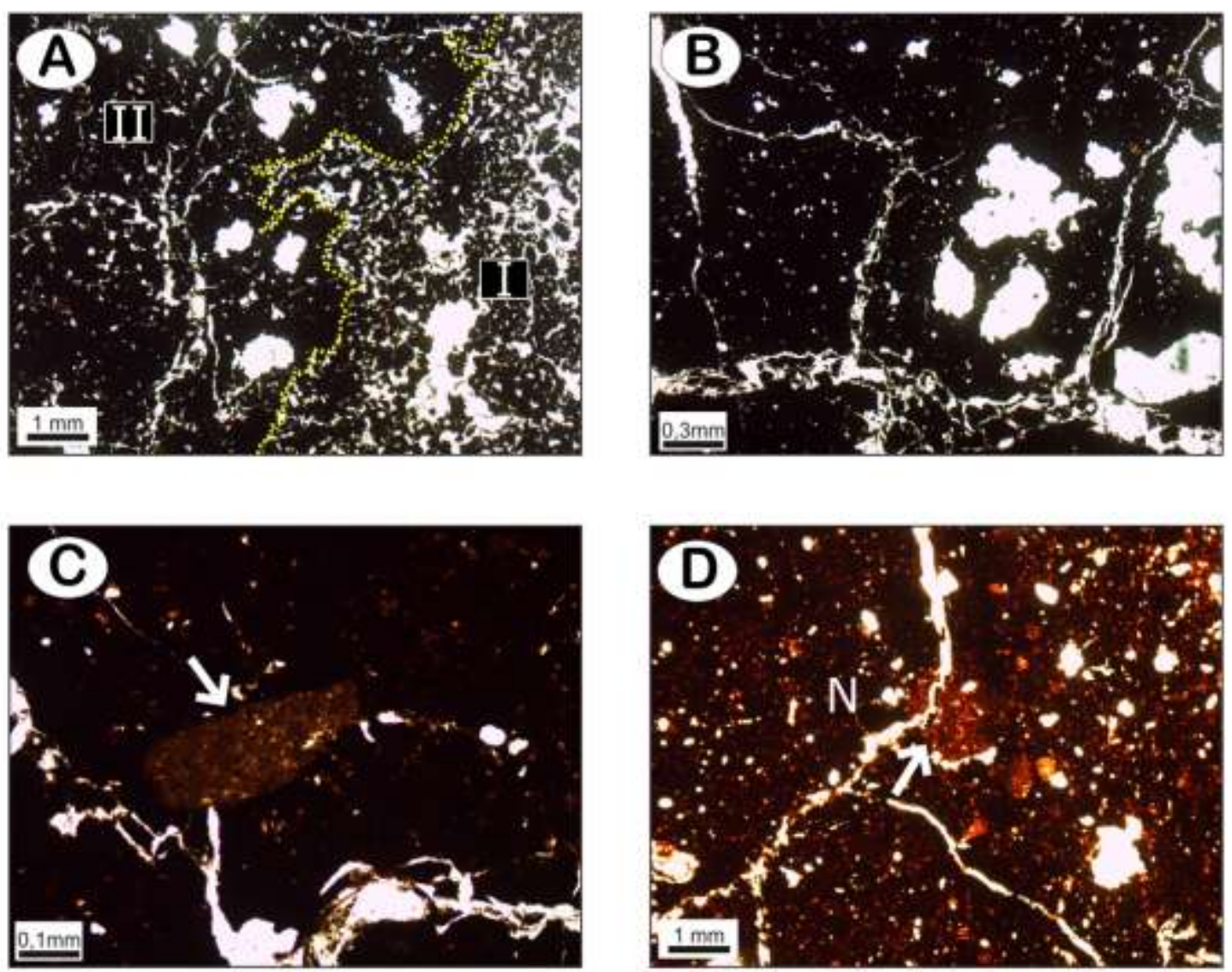

(A) DRC enauli-porfírica, microestruturas em blocos subangulares, microagregados (I) e cavitária (II); (B) Detalhe de microestrutura em blocos subangulares, poros em canais, cavitários e planares; (C) Detalhe (seta branca) de agregado pedogênico intrusivo (pedorrelíquia); (D) DRC porfírica aberta com fração grossa constituída por grãos de quartzo e nódulos. Pedofeição intrusiva cortada por poro canal (seta branca).

Fonte: modificado de Gazola, 2020.

Em materiais alóctones, poros cavitários formam-se no início do processo deposicional (sindeposicional) em que a circulação interna da água provoca mobilidade de $\mathrm{Fe}$ e $\mathrm{Mn}$ e desmantelamento parcial da matriz (PAISANI; PONTELLI, 2012). Poros vesiculares representam o aprisionamento de ar em fluxos viscosos, sobretudo em fluxos de 
lama (BERTRAN; TEXIER, 1999). Já os poros canais (pedotúbulos) representam a atividade biológica (KOOISTRA; PULLEMAN, 2010; MARCELINO; STOOPS; SCHAEFER, 2010). Essa última categoria de poros, associado as demais categorias, é importante, pois sugere que a bioturbação ocorreu concomitante aos processos de sedimentação. Na literatura esse fenômeno confere ao paleossolo característica que permite o enquadrar na categoria de acumulativo, cuja sedimentação ocorreu simultânea à pedogênese (SCHAETZL; ANDERSON, 2005).

O material que compõe a sequência inferior (co-alúvial) exibe DRC do tipo porfirienáulica (Quadro 1) (Figura 3A), implicando que predomina enáulica e localmente é encontrada porfírica. A microestrutura do material é do tipo granular e em microagregados, os quais dominam a fração grossa. Também são observados nessa fração nódulos e minerais primários (quartzo, ilmenita e magnetita), nos tamanhos de areia grossa a silte. Os poros são do tipo empilhamento complexo (predominante), cavitários e canais (Figura 3B).

Figura 3 - Imagens micrográficas da sequência inferior (co-aluvial), onde se percebe DRC enáulica constituída, principalmente, de agregados de solo acomodados como clastos-suportados com contatos parciais (pontuais, planares, côncaco-convexo a suturados)

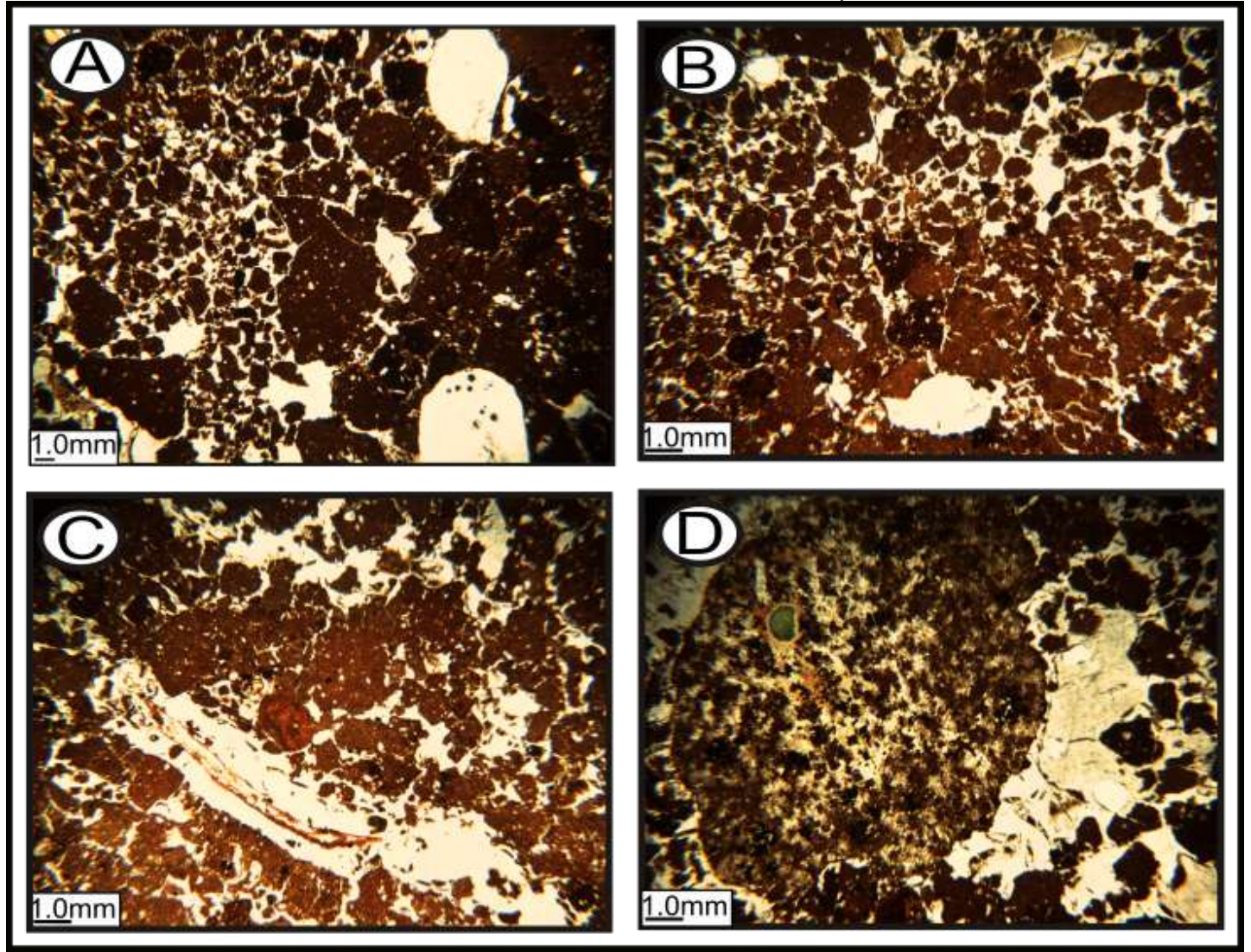

(A) DRC integrada do tipo porfiri-enáulica (LN). (B) Poros cavitários e empilhamento complexo (LN). (C) Biortubação moderna com fragmento de raiz com baixo grau de decomposição e nódulos intrusivos tamanho areia muito grossa a fina em fundo matricial enáulica tendendo a porfírica diante da compactação (LN). (D) Litorrelíquia de basalto (LN). LN: luz natural polarizada.

Fonte: Gazola, 2020. 
A micromassa apresenta cor 2.5YR 5/8 (vermelho) e birrefringência indiferenciada em manchas individuais pontilhadas. Na micromassaforam encontradas com baixa frequência pedofeições de depleção e de impregnação, como hiporevestimento de depleção e impregnação de poros. O grau de impregnação é de fraco a moderadamente impregnado com intercalação simples.

Com base nas características observadas, somada a macroestrutura tendendo a plano-paralela em que eles ocorrem, pode-se pensar que esse material com características granulares foi gerado pelo escoamento superficial e se manteve com tais características durante a sedimentação dentro da voçoroca, embora não se descarte que tenha ocorrido abrasão e quebra de agregados por ocasião da turbulência do fluxo canalizado (Figura 4) (HAO et al., 2019; WANG et al., 2013). Outro fato importante é que os sedimentos estão acomodados com diferentes tipos de contato, sobretudo suturados (Figura 4), sugerindo que eles passaram por diferentes graus de compactação (GUTIERREZ; NÓBREGA; VILAR, 2009), um dos mecanismos de consolidação após a sedimentação (LOWE, 1975).

A sequência intermediaria colúvial apresenta DRC integrada do tipo porfiri-enáulica (Quadro 1). A DRC enáulica apresenta poros de empilhamento complexo e compõem microestrutura granular a microagregada. Localmente eles formam microlaminações (Figura 4 A). Onde esses componentes se suturaram a DRC é porfírica. Poros cavitários e canais ocorrem localmente.

A fração grossa é constituída justamente pelo material granular e microagregado. Localmente encontram-se grãos de quartzo e outros minerais opacos (ilmenita ou magnetita) e litorrelíquias que ocorrem nas frações areia grossa a muito fina (Figura 4 F). A micromassa apresenta cor 2.5YR5/8 (vermelho) e birrefringência manchada a pontilhada. Foram encontradas pedofeições matrícas como hiporevestimento de depleção de poros vinculados aos agregados (Figura $4 \mathrm{C} \mathrm{e} \mathrm{E}$ ). Outras pedofeições intrusivas foram identificadas, como o preenchimento solto descontínuo nos poros canais (Figura 4 D).

Demais pedofeições, como hiporevestimento e quasi-revestimento estão vinculadas tanto pelo processo sindeposicional, quanto pós-deposicional. A desagregação do material e formação de hiporevestimento de depleção devem estar associadas ao processo de dessecação, posterior a sedimentação e infiltração da água. Já o preenchimento solto descontínuo, podem ser remanescentes de preenchimentos biogênicos de poros canais que flocularam durante o transporte (Figura 4D).

Com base na DRC integrada com nítidas microlaminações e microestrutura granular com sinais de abrasão mecânica, entende-se que o material seja de origem colúvial e que o transporte esteja vinculado à ação da água pelo processo de escoamento superficial (ARAUJO et al., 2017; BERTRAN et al., 1997; BIFFI; PAISANI, 2019). A 
microestrutura/porosidade cavitária indica a presença de água no processo sindeposicional e pós-deposicional.

Figura 4 - Imagens micrográficas da sequência intermediaria (colúvial)

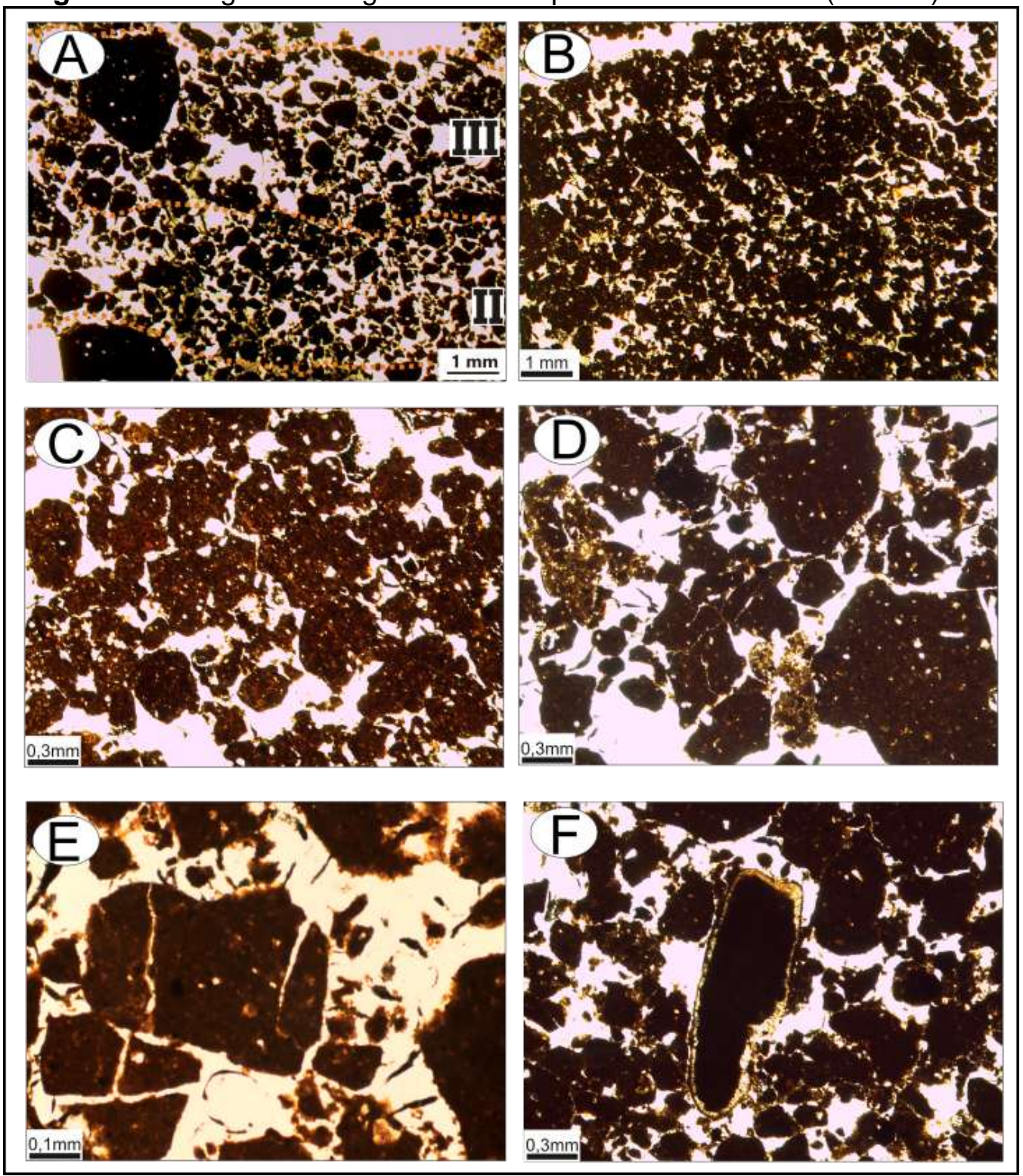

(A) DRC enáulica e microestrutura granular e microagregados em laminação suavemente inclinada observada diretamente na seção delgada (NC). (B) DRC integrada porfiri-enáulica variados tipos de contatos entre agregados com poros empilhamento complexo e cavitários (LN). (C) Detalhe do contato dos agregados. (D) Poros de empilhamento complexo (LN). (E) Agregados fragmentados por poros planares (LN). (F) Diferentes tipos de contatos entre os agregados com destaque para fragmento de mineral opaco com hiporevestimento de grão herdados da área fonte, possivelmente em material porfírico (matriz suportada) (LN). Laminações: I, II, III e IV. LN: luz natural polarizada. NC: nicóis cruzados.

Fonte: modificado de Gazola, 2020.

A presença de duas categorias de agregados evidência fontes distintas de sedimentos ao longo da encosta (BIFFI; PAISANI, 2019). Os agregados granulares apresentam sinais 
de contínuo retrabalhamento ao longo da encosta por escoamento superficial (HAO et al., 2019; WANG et al., 2013).

A sequência superior (colúvial) apresenta DRC do tipo porfírica aberta e localmente enáulica (enauli-porfírica) (Quadro 1) (Figura 5 D, F). Predominam poros cavitários seguidos de planares, canais e câmaras, o que imprime moderada a forte pedalidade (Figura 5 A, E). O material é pédico parcialmente acomodado em blocos subangulares e microagregados preenchendo poros biológicos.

A fração grossa consiste em nódulos, com forte a fraca impregnação de origem pedomórfica e litomórfica (Figura $5 \mathrm{~A}, \mathrm{C}$ ), quartzo, minerais isotrópicos (ilmenita/magnetita), litorrelíquias, pedorreliquías (Figura $5 \mathrm{~A}, \mathrm{C}$ e F), alterorrelíquias (Figura $5 \mathrm{~B}$ ); e localmente ocorre microartefato de zeólita tamanho grânulo (Figura 5 D).

A micromassa é de cor 2.5YR5/8 (vermelho) e exibe birrefringência em manchas agrupadas, localmente manchas pontilhadas. Pedofeições mátricas consistem em hiporevestimentos de depleção e de impregnação de poros e grãos, e raramente encontram-se revestimentos típicos e nódulos típicos de fraca a moderada impregnação. Essas microfeições associadas ao fundo matricial expressam fraca migração de óxidos de ferro e/ou manganês (SCHAETZL; ANDERSON, 2005), podendo representar fenômeno pósdeposicional.

As características micromorfológicas da sequência colúvial superior levam a pensar que o material tem gênese decorrente de discretos fluxos de lama com mistura de pedo- e litorrelíquias intrusivas ao fundo matricial porfírico. A presença de litorrelíquias, pedorrelíquias, alterorrelíquias, nódulos litomórficos e pedomórficos de forte impregnação dispostos de forma aleatória no fundo matricial sugere que esse nível pedoestratigráfico de origem coluvial derive de um horizonte de transição do tipo B/C (PAISANI; PONTELLI,2012). 
Figura 5 - Imagens micrográficas da sequência colúvial superior
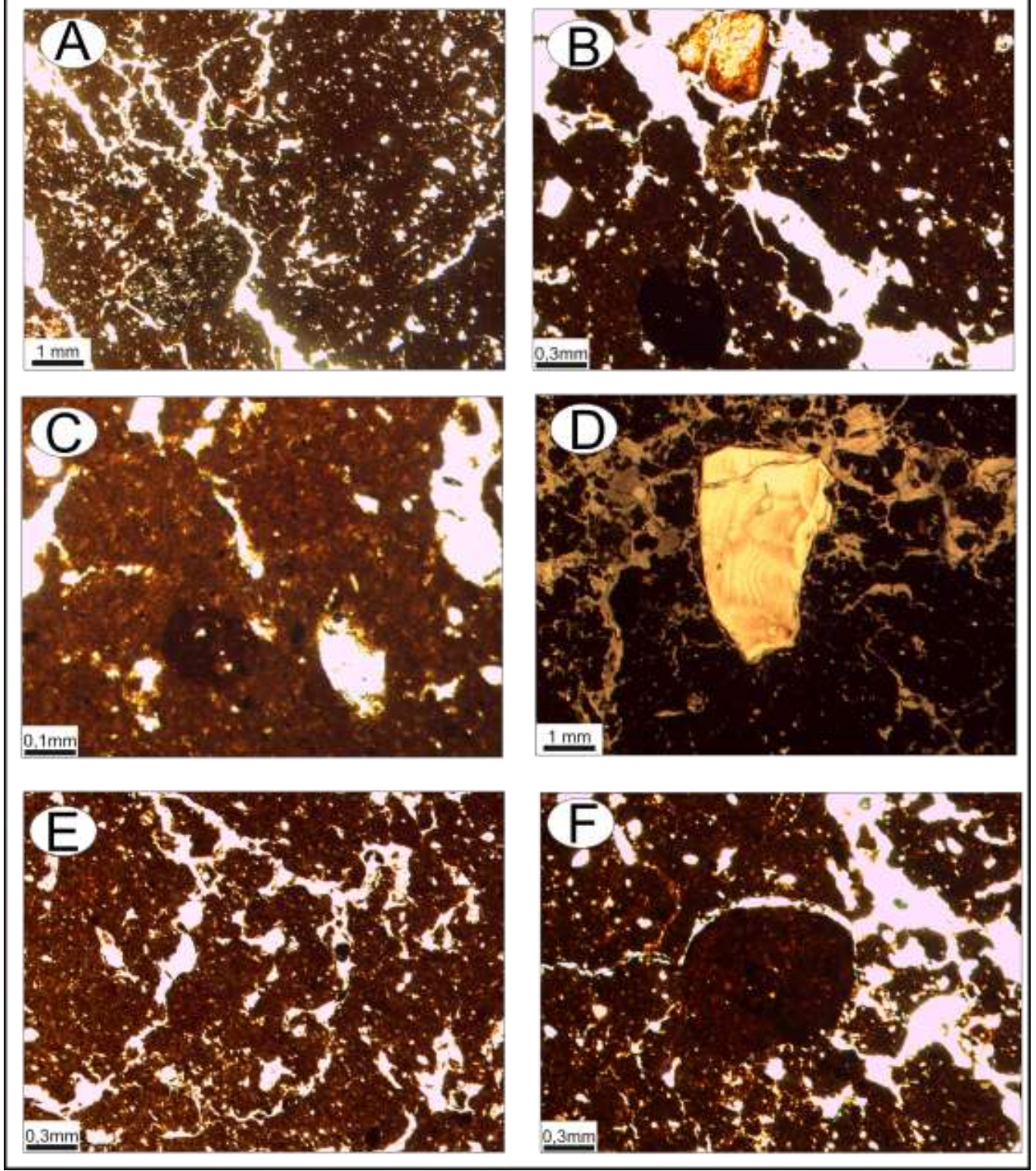

(A) Litorrelíquia e nódulos litomórficoscom forte impregnação intrusivos no fundo matricial - LN. (B) Alterorrelíquia e preenchimento solto descontínuo LN. (C) Nódulos de moderada a fraca impregnação LN. (D) Microartefato de zeólita (componente antropogênico intrusivo) na transição entre fundo matricial porfírico e câmara biogênica enáulica - LN. (E) Poros cavitários e DRC porfírica LN. (F) Agregado de solo intrusivo no fundo matricial (pedorrelíquia tipo agregado) LN. LN: luz natural polarizada. NC: nicóis cruzados.

Fonte: Gazola, 2020.

\section{CONSIDERAÇÕES FINAIS}

No Planalto das Araucárias são identificadas sequencias sedimentares inseridas em ambiente de encosta por vezes preenchendo incisões erosivas, cujos processos sedimentares são pouco conhecidos. Esse trabalho teve como objetivo verificar os processos responsáveis pela colmatação de paleocabeceira de drenagem da superfície 
geomorfológica de Pinhão/Guarapuava. Para isso, utilizou-se da descrição micromorfológica de microfácies balizadas nas chaves de interpretação identificadas na literatura.

O topo do paleossolo enterrado mostrou-se com propriedades micromorfológicas que permitem enquadrá-lo na categoria de paleossolo acumulativo, cuja sedimentação ocorreu concomitantemente à pedogênese. A parcial melanização do fundo matricial dificultou precisar os processos envolvidos na sedimentação. Pedorrelíquias presentes no fundo matricial mostram que o material corresponde a sedimentos retrabalhados pelo escoamento superficial, contudo o estágio de deposição final esteve vinculado a discretos movimentos de massa, possivelmente fluxos de lama que geraram depósito com predomínio de matriz suportada com clástos de fração grossa intrusivos.

A distribuição relativa dos constituintes revelou diferentes concentrações entre fração grossa, micromassa e porosidade entre as sequências sedimentares, indicando variações na concentração de sedimento e água nos fluxos que colmataram a paleocabeceira. A microestrutura granular/microagregado sugere o processo de escoamento superficial laminar. Já a microestrutura maciça indica fluxos densos, a princípio fluxos com matriz suportada como fluxos de lama.

Poros canais são identificados com frequência nos materiais analisados, e raramente modificam as estruturas sedimentares. Nesse sentido, é possível que essa categoria de poros tenha se formado em curtos episódios de estabilidade e progressão da atividade biológica entre os fluxos que colmataram a paleocabeceira de drenagem. Microfeições de depleção e impregnação indicam a ocorrência de água nos processos deposicionais e pósdeposicionais. Ocasionalmente, são identificados fragmentos de minerais primários (zeólitas) com sinais delascamento, interpretados como estilhas (microartefato arqueológico).

De forma geral, a descrição micromorfológica dos materiais serviu como chave para a interpretação dos processos deposicionais, em que foram reconhecidos diferentes processos em materiais aparentemente homogêneos em escala macroscópica. Sendo possível constatar, a princípio, a atuação do escoamento superficial estabelecendo incisão erosiva linear (voçoroca) que truncou o topo do paleossolo enterrado, formando as sequências inferior coluvial-aluvial (co-alúvial) e intermediaria colúvial. A partir da sequência superior coluvial fluxos de lama passaram a predominar na colmatação da cabeceira de drenagem. 


\section{REFERÊNCIAS}

ARAUJO, Astolfo Gomes de Melo et al. The "Lagoa do Camargo 1" Paleoindian site: some implications for tropical geomorphology, pedology, and paleoenvironments in southeastern Brazil. Geoarchaeology, New York, US, v. 32, n. 6, p. 1-16, 2017.

BERTRAN, Pascal et al. Fabric characteristics of subaerial slope deposits. Sedimentology, Oxford, GB, v. 44, p. 1-16, 1997.

BERTRAN, Pascal; TEXIER, Jean-Pierre. Facies and microfacies of slope deposits. Catena, Amsterdam, NL, v. 35, n. 2-4, p. 99-121, 1999.

BIFFI, Vitor Hugo Rosa. Evolução de encosta em contexto de paleocabeceira de drenagem da bacia do rio Capão Grande no quaternário tardio - superfície de Pinhão/Guarapuava. 2019. Dissertação (Mestrado em Geografia) - Universidade Estadual do Oeste do Paraná, Francisco Beltrão, PR, 2019.

BIFFI, Vitor Hugo Rosa; PAISANI, Julio Cesar. Micromorfologia de colúvio-alúvios em paleovoçorocas colmatadas nas Superfícies de Cimeira de Pinhão/Guarapuava e Palmas/Caçador - Sul do Brasil. Revista Brasileira de Geomorfologia, São Paulo, SP, v. 20, n. 4, p. 735-749, 2019.

CASTRO, Selma Simões de. Micromorfologia de solos: bases para descrição de lâminas delgadas. Campinas: UNICAMP; Goiânia: UFG, 2008.

CATT, John A. Paleopedology manual. Quaternary International, London, UK, v. 6, p. 1-95, 1990.

CHURCHMAN, G. Jock. The key role of micromorphology instudies of the genesis of clay mineral sand their association sin soil sand its relevance to advances in the philosophy of soil science. Turkish Journal of Earth Sciences, Ankara, Turkey, v.22, p.376-390, 2013.

EMBRAPA - Empresa Brasileira de Pesquisa Agropecuária. Sistema brasileiro de classificação de solos. Brasília, DF: EMBRAPA, 1999.

GAZOLA, Karina de Cássia. Dinâmica de encosta em contexto de cabeceira de drenagem na Superfície de Cimeira de Pinhão/Guarapuava no Quaternário Tardio. 2020. Dissertação (Mestrado em Geografia), Universidade Estadual do Oeste do Paraná, Francisco Beltrão, PR, 2020.

GUTIERREZ, Nelci Helena Maia; NÓBREGA, Maria Teresa de; VILAR, Orêncio Monje. Influence of the microstructure in the collapse of a residual clayey tropical soil. Bulletin of Engineering Geology and the Environment, Heidelberg, Alemanha, DE, v. 347, p. 107116, 2009.

$\mathrm{HAO}$, Haoxin et al. Water erosion processes and dynamic changes of sediment size distribution under the combined effects of rainfall and Overland flow. Catena, Amsterdam, NL, v. 173. p. 494-504, 2019.

HUGHES, Philip D. Geomorphology and quaternary stratigraphy: role of morpho-litho-and alloestratigraphy. Geomorphology, Amsterdam, NL, n. 123, p. 189-199, 2010.

IBGE. Manual Técnico da vegetação Brasileira. Rio de Janeiro, RJ: IBGE, 2012.

KOOISTRA, Maja J.; PULLEMAN, Mirjam M. Features related to faunal activity. In: STOOPS, Georges; MARCELINO, Vera; MEES, Florias (orgs.). Interpretation of micromorphological features of soils and regoliths. Amsterdam: Elsevier, 2010. p. 397418.

LIMA, Flavia Jorge de et al. Micromorfologia de colúvios em sequencias pedoestratigráfica e litoestratigráfica: o caso das Superfícies de Palmas/Água doce (Sul) e Planalto Sedimentar do Araripe (Nordeste do Brasil). Revista Brasileira de Geomorfologia, São Paulo, SP, v. 18 , n. 2, p. 329-348, 2017. 
LOWE, Donald R. Water escapes structures in coarse-grained sediments. Sedimentology, Oxford, GB, v. 22, p. 157-204, 1975.

MARCELINO, Vera; STOOPS, Georges; SCHAEFER, Carlos E. G. R. Oxic and related materials. In: STOOPS, Georges; MARCELINO, Vera; MEES, Florias (orgs.). Interpretation of micromorphological features of soils and regoliths. Amsterdam: Elsevier, 2010. p. 305-327.

MINEROPAR - Minerais do Paraná. O Grupo Serra Geral no Estado do Paraná. Curitiba, PR, 2013. 2v.

MÜCHER, Herman J.; MOROZOVA, Tatiana Dmitrievna. The application of soil micromorphology in quaternary geology and geomorphology. In: BULLOCK, Paul; MURPHY, Christopher P. (eds.). Soil micromorphology. Berkhamsted, UK: A B Academic Publishers, 1983. p. 151-194. v. 1: Techniques and Applications.

PAISANI, Julio César; PONTELLI, Marga E. Propriedades micromorfológicas de colúvios em encosta no médio vale do Rio Marrecas (Sudoeste do Estado do Paraná) - bases para distinção de formações superficiais alóctones e autóctones em substrato basáltico.

Pesquisas em Geociências, Porto Alegre, RS, v. 39, n. 1, p. 53-62, 2012.

PAISANI, Julio César et al. Pedogeochemistry and micromorphology of oxisols - a basis for understanding etchplanation in the Araucarias Plateau (Southern Brazil) in the Late Quaternary. Journal of South American Earth Sciences, Oxford, GB, v. 48, p.1-12, 2013.

PAISANI, Julio César et al. Paleosols in low-order stream sand valley heads in the Araucaria Plateau - record of continental environmental conditions in southern Brazil attheendof MIS 3. Journal of South American Earth Sciences, Oxford, GB, v. 54, p. 57-70, 2014.

PAISANI, Julio César et al. Evolução de paleocabeceira de drenagem do Rio Chopinzinho (Sul do Brasil) durante o Quaternário Superior. Revista Brasileira de Geomorfologia, São Paulo, SP, v. 17, n. 1, p. 43-59, 2016.

PAISANI, Julio César et al. Subtropical Araucaria Plateaus. In: SALGADO, André Augusto Rodrigues; SANTOS, Leonardo José Cordeiro; PAISANI, Julio César (orgs.). The physical geography of Brazil: environment, vegetation and landscape. Cham, Switzerland: Springer International Publishing, 2019a. p. 21-40.

PAISANI, Julio César et al.Paleoenvironmental dynamics oflow-order paleovalleys in the Late Quaternary - Palmas/Caçador Summit Surface - Southern Brazil. Catena, Amsterdam, NL, v. 182, p. 104-171, 2019b.

SCHAETZL, Randall J.; ANDERSON, Sharon. Soils: genesis and geomorphology. Cambridge, UK: Cambridge University Press, 2005.

SELBY, Michael John. Earth's changing surface: an introduction to geomorphology. New York: Oxford University Press, 1985.

STOOPS, Georges. Guidelines for analysis and description of soil and regolith thin sections. Madison, Wisconsin: Soil Science Society of America, 2003.

STOOPS, Georges; MARCELINO, Vera; MEES, Florias. Micromorphological features and their relation to processes and classification: general guidelines and keys. In: STOOPS, Georges; MARCELINO, Vera; MEES, Florias (orgs.). Interpretation of micromorphological features of soils and regoliths. Amsterdam: Elsevier, 2010. p. 15-35.

THOMAS, Michael F. Geomorphology in the tropics: a study of weathering and denudation in low latitudes. Chichester, UK: John Wiley \& Sons, 1994.

THOMAZ, Edivaldo Lopez; VESTENA, Leandro R. Aspectos climáticos de GuarapuavaPR. Guarapuava: UNICENTRO, 2003. 
Micromorfologia para Caracterização de Processos Deposicionais em Paleocabeceira no Planalto...

WANG, Jun-Guang et al. Effects of stability, transport flow. Soil and Tillage Research, Amsterdam, NL, v. 126, p. 134-142, 2013.

Recebido: março de 2020.

Aceito: julho de 2020. 